"Foreign direct investment and wage bargaining"

Robin Naylor and Michele Santoni

CSGR Working Paper No. 41/99

October 1999
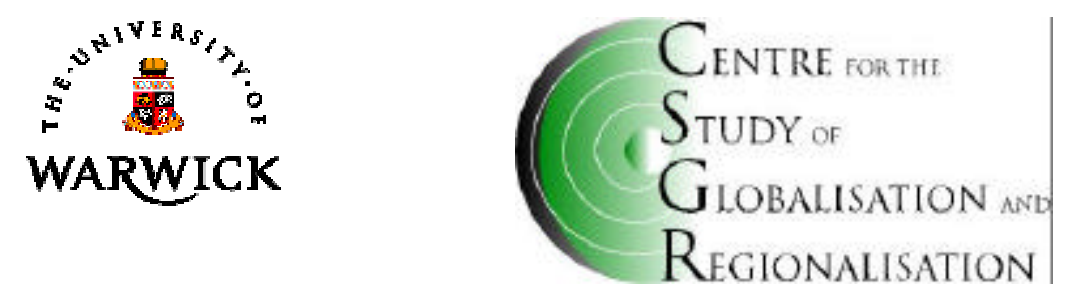


\title{
Foreign direct investment and wage bargaining
}

Robin Naylor and Michele Santoni ${ }^{1}$

Economics Department, Univeristy of Warwick and CEPR

CSGR Working Paper No. 41/99

October 1999

\begin{abstract}
:
We derive the sub-game perfect Nash equilibria for the foreign direct investment (FDI) game played between two unionised firms. Among other results, we show that FDI is less likely, ceteris paribus, the greater is union bargaining power, the stronger the weight the union attaches to wages, and the more substitutable are firms' products in the potential host country. We derive results concerning the conditions under which FDI will be reciprocal. We also examine conditions under which the FDI game between firms will possess the characteristics of a Prisoners' Dilemma. Finally, we consider the possibility that firms might delegate wage determination to unions as a method of strategic deterrence against entry by FDI.
\end{abstract}

Keywords: Foreign direct investment, oligopoly, wage bargaining.

JEL Classification: J51, L13, F12, F23.

Address for correspondence:

Robin Naylor; Michele Santoni

Department of Economics

University of Warwick

Coventry CV4 7AL, UK

Email: robin.naylor@warwick.ac.uk

Email: michele.santoni@warwick.ac.uk

\footnotetext{
${ }^{1}$ We would like to thank David de Meza, Norman Ireland, Mike Waterson, and an anonymous referee of this Journal for helpful comments. The paper also benefited from discussions with participants at the 1998 Royal Economic Society Conference (RES, Warwick), the 1998 Econometric Society European Meeting (ESEM98, Berlin), the 1998 Conference of the European Association of Researchers in Industrial Economics (EARIE98, Copenhagen), the 1998 Conference of the European Association of Labour Economists (EALE98, Blankenberge), and at seminars at the universities of Aarhus and Cagliari.
} 


\section{Introduction}

Of all the flows of foreign direct investment into countries of the European Union, the proportion originating within the EU itself represents the majority. Furthermore, this proportion is rising. Dunning (1997a), for example, records that in the period 1991-93, 69.2\% of FDI flows into EU countries originated within Western Europe (and 59\% within the EU itself; see also Barrel and Pain, 1997). This represented a growing fraction when compared with earlier periods: in 1984-87, for example, the equivalent figure was $58.5 \%$ from within Western Europe. An important factor in this growth is the package of measures associated with the Internal Market Programme of the EU (see Dunning, 1997b). Furthermore, just as it is well-established that a major part of intra-EU trade takes the form of intra-industry trade (see, for example, Greenaway and Milner, 1986, and European Commission, 1996), so it emerges that a significant proportion of within-EU FDI consists of intra-industry FDI (see Dunning, 1997b).

In this paper, we develop a model of cross-border firms' FDI choices in which we abstract from the possibility of trade as an alternative mode of supplying the foreign market. For the majority of FDI flows in the EU this is the relevant case to consider: from 1984 to 1993, the service sector accounted for almost two thirds of cumulative FDI inflows (see Sapir 1993). As services are, in general, relatively non-tradable, FDI is often the only option for a firm wanting to capture a share of a foreign market. ${ }^{1}$ In developing a model of two-way intraindustry foreign direct investment (henceforth, RFDI- 'reciprocal' FDI) which is relevant to non-traded goods, it is appropriate to adopt a framework in which product markets are characterised by imperfect competition. For example, financial services in Europe are typically characterised by high concentration ratios, whilst both banking and transportation services are commonly described as oligopolistic (see Sapir, 1993).

In the current paper, cross-border firms choose independently whether or not to carry out FDI in the rival market. We consider the possible Nash equilibria to this game and focus on the issue of how the nature of the equilibrium depends upon both the extent of union bargaining power and the nature of product market competition. From OECD data, it is clear that the incidence of unionisation in service sector employment is not insignificant. Indeed, rates of membership in a number of services typically exceed the average for manufacturing

\footnotetext{
${ }^{1}$ For instance, consider the establishment of EU insurance companies in France: '...At present companies from EU countries can sell their products either by establishing themselves in another country, or by carrying out
} 
in Europe. For example, in transport and communications, union membership density is $72 \%$ in Italy and $62 \%$ in the UK against manufacturing averages of $47 \%$ and $42 \%$ for the two countries in 1988 (see OECD, 1991). In financial services, on the other hand, the average membership rate in Italy is $22 \%$ and in the UK is $25 \%$. Nonetheless, these figures are not trivial and are likely to under-estimate the extent of union coverage in those sectors.

The literature on strategic FDI (cf. e.g. Smith, 1987, and Hortsmann and Markusen, 1987) has begun to incorporate a formal analysis of the effects of trade unions on firms' choices. Bughin and Vannini (1995) consider the case in which a 'foreign' firm chooses between a (costless) export and an FDI strategy. They find that fully centralised unionisation deters FDI, if the foreign plant in the host market is also unionised, whereas it is an incentive to FDI if the foreign plant can hire workers at the competitive wage. Zhao $(1995,1998)$ considers a setting somewhat similar to ours, but focuses on labour rather than product market incentives. Zhao (1995), for example, shows that symmetric cross-hauling FDI raises the multinational firm's conflict payoff above zero, which in turn reduces the negotiated wage for every level of employment, and increases the firm's total profits. Therefore, unionisation induces reciprocal FDI: essentially, firms use FDI as a divide-and-rule strategy. Zhao assumes a global product market. In contrast, we assume that product markets are national rather than global and hence the main motive driving FDI is the capture of foreign market share and associated oligopoly rents.

The rest of the paper is organised as follows. In Section 2, we develop a model of a non-cooperative FDI game between two unionised cross-border firms. We are able to establish reasonably general conditions under which FDI is more likely to occur in a subgame perfect Nash equilibrium. We also derive results concerning the conditions under which FDI will be reciprocal. Finally, we consider the possibility that the FDI game will possess the characteristics of a prisoners' dilemma. In Section 3, we consider more specific functional forms and, in particular, we examine the impact of the degree of product market substitutability on the FDI equilibria. We observe that firms have incentives to deter entry into their domestic markets through FDI and, in Section 4, we analyse one method of strategic entry deterrence available to a firm in the form of delegating wage determination to the domestic union. Section 5 closes the paper with conclusions and further remarks. 


\section{The general model}

In this section, we develop a model of a non-cooperative three-stage game played by two (unionised) firms (Firm 1 and Firm 2) based in two countries (A and B, respectively). In each country there is a 'self-contained' product market with no international trade in goods across the two markets. In Stage 1 of the game, each firm chooses independently whether or not to make a foreign direct investment (FDI) in the other country. The FDI consists of the establishment of a production plant in the other country at a sunk cost: $F_{1 B}\left(F_{2 A}\right)$ represents the cost to Firm 1 (Firm 2) of investing in Country B (A). We interpret this cost as equivalent to a payment, such as a licence fee, for the rights to establish a plant in a foreign country. ${ }^{2} \mathrm{We}$ assume that all plants are unionised. In Stage 2, the wage is determined in each plant as a result of (decentralised) bargaining between local management and the local union. In Stage 3, firms choose output (and hence employment) to maximise profits either as local monopolists or as Cournot duopolists, depending on the Stage 1 choices over FDI by the two firms. Because there is no trade between countries, the only way for Firm 1 (2) to capture a share of the Country B (A) market is to engage in FDI there.

The modelling strategy we adopt to investigate this problem is the following. First, in sub-section 2.1, we consider the Stage 1 game under very general assumptions about demand. We allow for the two countries to be different in all relevant respects. We establish that the FDI game is characterised by strategic dominance and that whether or not a firm will make a foreign direct investment will depend upon the size of the potential capturable duopoly profits in the host country, relative to the fixed costs of the investment. In sub-sections 2.2 and 2.3, we consider the determinants of these duopoly profits. The analysis proceeds by backward induction: sub-section 2.2 presents the analysis of the Stage 3 output-setting game played by firms in the host-country product market and sub-section 2.3 considers the Stage 2 wagebargaining game. Sub-section 2.4 returns to the analysis of the Stage 1 FDI game and derives general results concerning the properties and determinants of the sub-game perfect Nash equilibrium solution to the model. In sub-section 2.5 , we consider the conditions under which the FDI game might exhibit the characteristics of a prisoner's dilemma. In Section 3 of the paper, we then make more precise assumptions about specific functional forms in order to generate more particular results concerning both the influences on and the properties of the different possible FDI equilibria.

\footnotetext{
${ }^{2}$ Equally, the fixed cost associated with FDI could be interpreted as a sunk cost of investment.
} 


\subsection{Stage 1 The FDI game and strategic dominance}

As each firm has two possible strategies in Stage 1, there are three distinct types of outcome to the FDI game: (i) Reciprocal Foreign Direct Investment (RFDI), in which both firms play the FDI strategy; (ii) Autarky, in which neither firm makes the investment (both play NFDI); and (iii) Asymmetric Foreign Direct Investment (AFDI), in which only one of the firms makes the investment. The Stage 1 game is summarised in Figure 1.

Figure 1. The Stage 1 Game

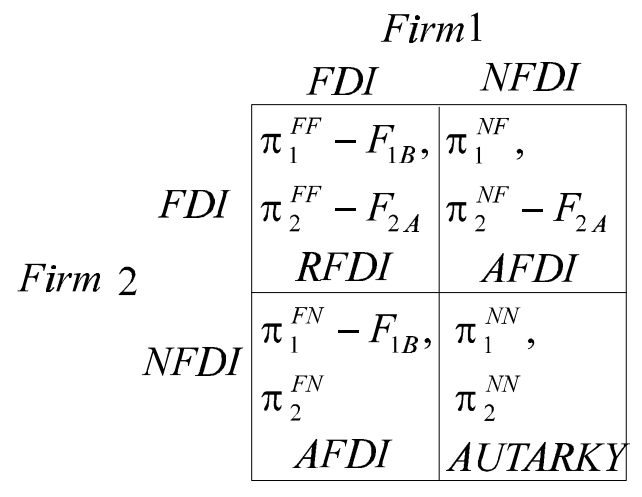

where $\pi_{1}{ }^{F F}, \pi_{1}{ }^{F N}\left(\pi_{1}{ }^{N F}\right), \pi_{1}{ }^{N N}$ represent the Firm 1's variable profits, when, respectively: both firms play the FDI strategy, when Firm 1 plays FDI and Firm 2 NFDI (and vice-versa), and when both firms play NFDI.

Under the quite general assumptions we have made so far, we are able to establish the result reported under Lemma 1.

Lemma 1 Each firm has a dominant strategy with respect to its Stage 1 choice over FDI. Whether the dominant strategy is to make the foreign direct investment or not depends on the magnitude of variable profits arising from FDI relative to the fixed cost incurred.

This result arises because of the segmentation of the two product markets: that is, from the fact that product markets are assumed to be domestic, rather than global, coupled with the assumption that, as is generally reasonable for the case of services, there is no international trade in goods across national boundaries.

The proof of Lemma 1 is readily demonstrated in terms of the payoffs represented in Table 1. Suppose Firm 2 plays FDI. Then Firm 1 will prefer to play FDI also so long as:

$\pi_{1}^{F F}-F_{1 B}>\pi_{1}^{N F}$ 
where $\pi_{1}^{F F}$ is made up of profits from domestic sales in the event of duopoly in the home market $\left(\pi_{1 A}{ }^{d}\right.$ ), plus profits from foreign sales when market B is also characterised by duopoly $\left(\pi_{1 B}{ }^{d}\right) . \pi_{1}{ }^{N F}$, on the other hand, consists solely of Firm 1's share of domestic duopoly profits $\left(\pi_{1 A}{ }^{d}\right)$. Thus, condition (1) can be re-written as:

$$
\begin{array}{ll} 
& \pi_{1 A}{ }^{d}+\pi_{1 B}{ }^{d}-F_{1 B}>\pi_{1 A}{ }^{d} \\
\text { or, } \quad \pi_{1 B}{ }^{d}>F_{1 B}
\end{array}
$$

If, instead, Firm 2 plays NFDI, then Firm 1 prefers FDI if:

$$
\pi_{1}^{F N}-F_{1 B}>\pi_{1}{ }^{N N}
$$

where $\pi_{1}{ }^{F N}$ is made up of profits from monopoly sales in the home market $\left(\pi_{1 A}{ }^{m}\right)$, plus profits from foreign sales when market B is characterised by duopoly $\left(\pi_{1 B}{ }^{d}\right) . \pi_{1}^{N N}$, on the other hand, consists only of Firm 1's domestic monopoly profits $\left(\pi_{1 A}{ }^{m}\right)$. Thus, condition (3) can be re-written as:

$$
\begin{array}{ll} 
& \pi_{1 A}{ }^{m}+\pi_{1 B}{ }^{d}-F_{1 B}>\pi_{1 A}{ }^{m} \\
\text { or } \quad \pi_{1 B}{ }^{d}>F_{1 B}
\end{array}
$$

Clearly, conditions (2) and (4) are identical: Firm 1 has a dominant strategy in the Stage 1 FDI game. For Firm 1, the dominant strategy is to play FDI (NFDI) if:

$$
\pi_{1 B}{ }^{d}>(<) F_{1 B}
$$

Analogously, Firm 2 will play FDI (NFDI) if:

$$
\pi_{2 A}^{d} \quad F_{1 B} \quad F_{2 A}
$$

One corollary of Lemma 1 is that the Nash equilibrium solution to the FDI game described in Figure 1 will be unique. ${ }^{3}$ This follows because the outcome is a dominant strategy equilibrium. Any one of the four outcomes described in the payoff matrix represented in Figure 1 is a potential sub-game perfect Nash equilibrium, depending upon the particular

\footnotetext{
${ }^{3}$ This assumes that a unique Nash equilibrium exists in each of Stages 2 and 3 of the game: see Appendices 1 and 2, below.
} 
values of the variable profits and of the fixed costs of making FDI in each of the two countries. From conditions (5) and (6), it is clear that, for each firm, we need consider only the variable profits associated with the foreign duopoly which would result from FDI by that firm. ${ }^{4}$

In order to analyse the determinants of sub-game equilibrium profits of the two firms, and hence to solve the Stage 1 FDI game, we need to examine Stages 2 and 3: respectively, the wage-bargaining and output-setting stages of the game. We proceed to analyse the game by the customary method of backward induction.

\subsection{Stage $3 \quad$ Output-setting under FDI-induced duopoly}

Although we are not imposing symmetry across countries, we assume initially that within any particular country firms are identical with respect to technology and to conditions characterising both costs and product demand. This means, for example, that when we consider wage bargaining we can consider either centralised or decentralised bargaining arrangements, but require that both firms within a country confront equally powerful unions. Initially, we confine ourselves to the case of decentralised (plant-level) bargaining.

In order to focus exclusively on the effects of unionisation, we assume that products are homogeneous. ${ }^{5}$ The inverse product demand curve facing Firm 1 in Country B, for example, is given by: $p_{B}=p\left(x_{1 B}+x_{2 B}\right)$ where $p_{B}$ is continuous and twice differentiable with $p^{\prime}()<.0 . x_{1 B}$ denotes (foreign) production by Firm 1 and $x_{2 B}$ is (home) production by Firm 2. Within Country B, firms have symmetric constant-returns-to-labour technologies. The foreign profits of Firm 1 are given by $\pi_{1 B}^{d}=\left[p_{B}\left(x_{1 B}+x_{2 B}\right)-w_{1 B}\right] x_{1 B}$, and the home profits of Firm 2 are $\pi_{2 B}^{d}=\left[p_{B}\left(x_{1 B}+x_{2 B}\right)-w_{2 B}\right] x_{2 B} . w_{1 B}, w_{2 B}$ denote the wage rate in the home and foreign firms, respectively. Wages are predetermined at this stage. If the product market game is played in strategic substitutes, it can be shown that:

Lemma 2 Duopoly profits are decreasing in the common wage rate in a symmetric ${ }^{6}$ equilibrium.

\footnotetext{
${ }^{4}$ Notice that Lemma 1 is independent of whether the oligopoly is described by Cournot or by Bertrand competition.

${ }^{5}$ This assumption will be relaxed for the case considered in Section 3, below.

${ }^{6}$ Symmetry here refers to symmetry across firms within a country.
} 
See Appendix 1 for a demonstration of this result.

Lemma 2 holds so long as demand curves are not too strongly convex, as in such a case it would be possible for the Cournot game to be played in strategic complements, and this would change the properties of the equilibrium. de Meza (1982) and Seade (1985) have derived similar results under the assumptions of exogenous and constant marginal costs. Given Lemma 1, one implication of Lemma 2 is that FDI by a firm is more likely the lower is the equilibrium wage rate in the host country. We now turn to the determination of the (symmetric) equilibrium wage in Country B under unionisation.

\subsection{Stage $2 \quad$ Wage-bargaining under unionised duopoly}

As stated above, we are assuming that wage bargaining occurs at the plant level between each firm and its plant union. For Firm 1 in Country B, for example, the trade union has the following preferences: $S_{1 B}=\left[u\left(w_{1 B}\right)-u\left(\bar{w}_{B}\right)\right]\left(x_{1 B}\right)^{\theta}$. Following Dowrick (1989, p. 1126), we assume that $\mathrm{u}($.$) is continuous and twice differentiable, with \mathrm{u}^{\prime}()>$.0 , and either $\mathrm{u}^{\prime \prime}() \leq$.0 or $\left[\mathrm{u}^{\prime}(.) \mathrm{w} / \mathrm{u}^{\prime}().\right]=\mathrm{r}, \mathrm{r}$ being the constant Arrow-Pratt measure of relative risk aversion. $\bar{w}_{B}$ represents the wage paid to non-unionised workers in Country B. This is treated as given by the negotiators. $\theta \geq 0$ is the elasticity of the union's utility relative to employment (i.e., its relative preference for employment).

In order to model the wage negotiation, we use the Nash bargaining solution. For wage determination for Firm 1 in Country B, we have the Nash maximand:

$$
N A_{1 B}=\left[\pi_{1 B}{ }^{d}\left(w_{1 B}, \mathrm{w}_{2 \mathrm{~B}}\right)-\bar{\pi}_{B}\right]^{\beta_{B}}\left\{\left[u\left(w_{1 B}\right)-u\left(\bar{w}_{B}\right)\right] x\left(w_{1 B}, w_{2 B}\right)^{\theta}-\bar{S}_{B}\right\}^{1-\beta_{B}}
$$

where $0 \leq \beta_{B} \leq 1$ denotes the exogenous bargaining power of Firm 1, and which we assume to be symmetric across plants within a country. $\bar{\pi}_{B}$ and $\bar{S}_{B}$ represent the country-specific conflict payoffs to the firm (more correctly, the plant) and to the union, respectively. We assume conflict payoffs are exogenous and set equal to zero.

We assume that, within a country, the wage bargaining process occurs at both plants simultaneously and independently: each bargaining pair taking as given the outcome of the 
wage negotiation in the other union-plant bargaining pair. If the wage game is played in strategic complements, we can show that: ${ }^{7}$

Lemma 3 In a symmetric equilibrium, the wage rate is decreasing in the firm's bargaining power and in the union's preference for employment.

See Appendix 2 for a demonstration.

We now apply the results reported in each lemma above to the analysis of the Stage 1 FDI game.

\subsection{Stage 1 solution: sub-game perfect Nash equilibrium}

With respect to the FDI decision of an individual firm, we are able to establish Proposition 1.

Proposition 1 Foreign direct investment in a potential host country is more likely by a firm: (i) the weaker is union wage-bargaining power in that country, and (ii) the stronger is the union's preference for employment in that country.

The proposition follows directly from Lemmas 1, 2 and 3.

Proposition 1 is consistent with the well-known 'under-investment' result of Grout (1984), which arises when the firm and union are unable to write a binding long-term wage contract before the firm has taken the investment decision. Our analysis extends the result both to the case of the oligopolistic product market ${ }^{8}$ and to the case of FDI. In essence, unionisation, by reducing expected profits, discourages entry.

From (5), we know that Firm 1 will make the FDI investment in Country B so long as $\pi_{1 B}{ }^{d}>F_{1 B}$ and from the foregoing analysis we also know that $\pi_{1 B}{ }^{d}$ is likely to be increasing in $\beta_{B}$, the firms' bargaining power over wages in Country B. Thus, under continuity, there will be a locus of points in $\left(\beta_{B}, F_{1 B}\right)$-space for which $\pi_{1 B}{ }^{d}\left(\beta_{B}, F_{1 B}\right)=\pi_{1 B}{ }^{d}-F_{1 B}=0$. This

\footnotetext{
${ }^{7}$ Notice that the conditions of Lemma 2 and 3 are satisfied, for example, if the product market demand curve is linear.

${ }^{8}$ A similar result is derived in Rovida (1995) under the assumption of linearity of demand.
} 
indifference schedule will be monotonically upward-sloping given the results we have so far obtained. In Figure 2a, we represent this schedule graphically: below the indifference schedule $\pi_{1 B}\left(\beta_{B}, F_{1 B}\right)=0$, Firm 1 unambiguously prefers FDI to NFDI, and vice-versa above this schedule. We also show in Figure 2a the analogous indifference schedule for Firm 2: $\pi_{2 A}\left(\beta_{A}, F_{2 A}\right)=\pi_{2 A}{ }^{d}-F_{2 A}=0 .{ }^{9}$ Figure 2 a shows that there are four possible types of sub-game perfect Nash equilibrium in the Stage 1 game. If $\beta$ is sufficiently high in both countries and FDI costs are sufficiently low, then the equilibrium will be characterised by two-way FDI (i.e., RFDI). Autarky will prevail when the opposite conditions prevail. Finally, there will be asymmetric FDI (AFDI) when the two countries are sufficiently different with respect to the parameters, $F$ and $\beta$. One-way FDI will be in the direction of the country with relatively low values of both $F$ and $\beta$.

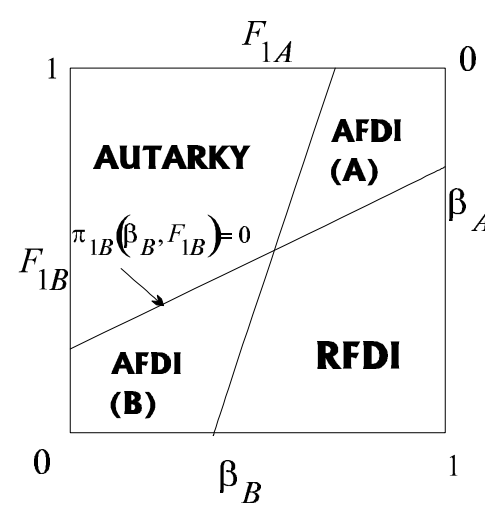

Figure 2a

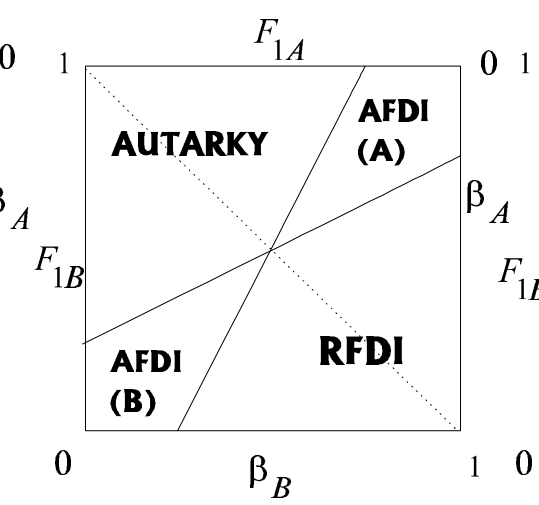

Figure 2b

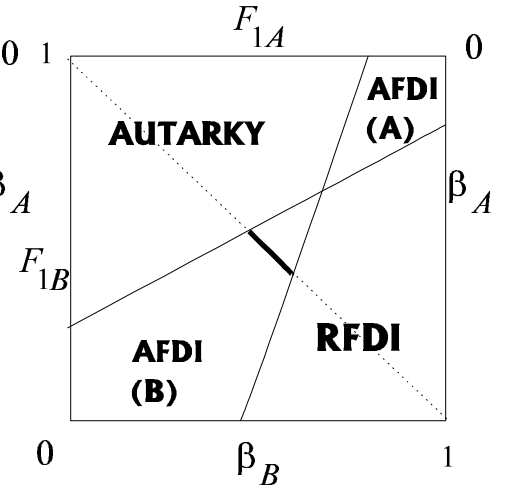

Figure 2c

Figure $2 \mathrm{~b}$ depicts the special case in which there is symmetry across the two countries in the parameters underlaying the respective indifference relations. Hence, each indifference relation is just the mirror image of the other, and they must intersect at the centre of the unit square. If each of $\beta$ and $F$ is also identical across countries $\left(\beta_{A}=\beta_{B}\right.$ and $\left.F_{2 A}=F_{1 B}\right)$, then there are only two possible equilibria: autarky or RFDI. AFDI is ruled out, as one would expect in the event of absolute symmetry. ${ }^{10}$ Of course, if there is symmetry across countries only over the parameters $\beta$ and $F$, then AFDI is a possible equilibrium: such a case is

\footnotetext{
${ }^{9}$ For the purposes of the graphical representation, the fixed costs of FDI are represented without loss of generality along the unit interval. In this way, for illustrative purposes, the indifference relations are drawn on the unit square, and are represented as monotonic functions with a single-crossing point.

${ }^{10}$ Note that we are considering only pure-strategy equilibria.
} 
shown in Figure 2c. These properties of the model are summarised in the following propositions.

Proposition 2 RFDI is more likely: (i) the greater is $\beta$ in both countries, (ii) the greater is $\theta$ in both countries, and (iii) the lower is $F$ in both countries.

Proposition 3 AFDI can be an equilibrium in pure strategies, even if $\beta, \theta$ and $F$ are the same across countries, so long as there are technology or product market differences across the two countries generating differences in the variable profit functions.

It is to the possible causes of such differences across countries that we turn our attention in Section 3. To do so, and in order to investigate the possible comparative static and welfare properties of the possible equilibria, we introduce more specific assumptions concerning functional form. First, however, we demonstrate in sub-section 2.5 the fact that for certain values of the costs associated with FDI, the FDI game between firms will have the characteristics of a prisoner's dilemma. From this, it follows that firms may have an incentive to collude over strategies of entry deterrence: this is then the subject of our analysis in Section 4.

\subsection{The FDI game as a prisoner's dilemma}

We have shown in conditions (4) and (5) that the sub-game perfect Nash equilibrium is RFDI if both $\pi_{1 B}^{d}>F_{1 B}$ and $\pi_{2 A}^{d}>F_{2 A}$. We assume for the purposes of this sub-section of the paper that there is symmetry across the two countries: hence, $\pi_{1 B}^{d}=\pi_{2 A}^{d}=\pi^{d}$ and $F_{1 B}=F_{2 A}=F$. It follows that RFDI is the SPNE of the game if:

$$
\pi^{d}>F
$$

From Figure 1, it follows that, under symmetry across countries, RFDI will, in Nash equilibrium, be Pareto inferior to Autarky if both condition (8) is satisfied and:

$$
\pi_{1 A}^{d}+\pi_{1 B}^{d}-F<\pi_{1 A}^{m},
$$

or

$$
2 \pi^{d}-F<\pi^{m}
$$


Hence, from (8) and (9), it follows that the FDI game will be characterised by the prisoner's dilemma (PD) in which an RFDI Nash equilibrium is Pareto-dominated by Autarky if $F$ is such that:

$$
\pi^{d}>F>2 \pi^{d}-\pi^{m}
$$

The greater is the interval between $\pi^{d}$ and $2 \pi^{d}-\pi^{m}$, the more likely it is that the game will

possess PD attributes, i.e. the greater $\left[\pi^{d}-\left(2 \pi^{d}-\pi^{m}\right)\right]$, or $\left[\pi^{m}-\pi^{d}\right]$. In other words, the greater is the excess of monopoly profits over oligopoly profits, the more likely it is that the FDI game will be a PD. The description of the game as a PD has important implications for incentives by firms with respect to strategic entry deterrence. We return to this and to the determinants of the disparity between monopoly and oligopoly profits in Sections 3 and 4.

\section{Specific functional forms: the linear model with differentiated products}

In this section of the paper, the structure of the game is as described in the previous section, but we make specific assumptions about the functional forms describing product demand, production and union utility. We also allow for the possibility that the products of the two firms are not perfect substitutes. We assume the following system of linear demands:

$$
\begin{aligned}
& p_{1 A}\left(x_{1 A}, x_{2 A}\right)=a_{A}-c_{A} x_{2 A}-x_{1 A} \\
& p_{2 A}\left(x_{1 A}, x_{2 A}\right)=a_{A}-c_{A} x_{1 A}-x_{2 A} \\
& p_{1 B}\left(x_{1 B}, x_{2 B}\right)=a_{B}-c_{B} x_{2 B}-x_{1 B} \\
& p_{2 B}\left(x_{1 B}, x_{2 B}\right)=a_{B}-c_{B} x_{1 B}-x_{2 B}
\end{aligned}
$$

where $p_{i j}$ denotes the price of commodity $\mathrm{i}=\{1,2\}$ in country $\mathrm{j}=\{\mathrm{A}, \mathrm{B}\}, x_{i j}$ is the output produced by Firm i in country $\mathrm{j}$, and $0<c_{j} \leq 1$ represents the degree of substitutability between the commodities produced by the two firms in country $\mathrm{j}$. As $c_{j}$ tends to unity, the two firms' products become increasingly perfect substitutes: if $c_{j}$ tends to zero the goods become increasingly independent. ${ }^{11}$

\footnotetext{
${ }^{11}$ See Singh and Vives (1984) for a further discussion.
} 


\subsection{Stage 3}

As we have shown in Section 2, the nature of the equilibrium to the FDI game depends crucially on the determinants of variable profits within each country. Consider first the Stage 3 duopoly game in Country B, for example. Firm 1's variable profits in Country B, $\pi_{1 B}{ }^{d}$, are given by:

$$
\pi_{1 B}^{d}=\left(a_{B}-c_{B} x_{2 B}-x_{1 B}-w_{1 B}\right) x_{1 B}
$$

where wages are pre-determined in Stage 2. For Firm 2, domestic variable profits under duopoly, $\pi_{2 B}{ }^{d}$, are given by:

$$
\pi_{2 B}^{d}=\left(a_{B}-c_{B} x_{1 B}-x_{2 B}-w_{2 B}\right) x_{2 B}
$$

Under the assumption of Cournot competition in the product market, the first-order conditions from (15) and (16) yield, for Country B, the following labour demand equations in terms of the wage levels of the two firms:

$$
\begin{aligned}
& x_{1 B}^{*}=\frac{1}{4-c_{B}^{2}}\left[\left(2-c_{B}\right) a_{B}-2 w_{1 B}+c_{B} w_{2 B}\right] \\
& x_{2 B}^{*}=\frac{1}{4-c_{B}^{2}}\left[\left(2-c_{B}\right) a_{B}-2 w_{2 B}+c_{B} w_{1 B}\right]
\end{aligned}
$$

where $x_{i B}^{*}$ denotes profit-maximising output of firm i.

Substituting equations (17) and (18) into (15) and (16), we can derive expressions for each firm's profit in terms of the wage levels of both firms. For Firm 1, for example, optimal profits are given by:

$$
\pi_{1 B}^{d}=\left[\frac{1}{4-c_{B}^{2}}\left[\left(2-c_{B}\right) a_{B}-2 w_{1 B}+c_{B} w_{2 B}\right]\right]^{2}=\left(x_{1 B}^{*}\right)^{2}
$$

\subsection{Stage 2}

We describe union preferences by a Stone-Geary utility function for the case of rentmaximisation, and we assume that the employer has the right-to-manage, i.e. that the union 
has no direct influence on employment. ${ }^{12}$ Hence, the objective of the union at Firm 1's foreign plant in Country $\mathrm{B}$, for example, is given by:

$$
S_{1 B}^{d}=\frac{w_{1 B}-\bar{w}_{B}}{4-c_{B}^{2}}\left[\left(2-c_{B}\right) a_{B}-2 w_{1 B}+c_{B} w_{2 B}\right]
$$

after substitution of the labour demand equations (17) and (18) and where $\bar{w}$ is countryspecific and represents the (constant) wage paid to non-unionised workers. Hence, from (19) and (20), the Nash maximand is given by:

$$
N A_{1 B}^{d}=\left[\pi_{1 B}^{d}-\bar{\pi}_{B}\right]^{\beta_{B}}\left[S_{1 B}^{d}-\bar{S}_{B}\right]^{1-\beta_{B}}
$$

where $\bar{\pi}_{B}$ and $\bar{S}_{B}$ represent the fallback payoffs to the firm (more correctly, the plant) and the union, respectively.

That there is a possible divide-and-rule incentive to FDI is well-known (see, for example, Cowling and Sugden, 1994, ch.4). ${ }^{13}$ We abstract from such mechanisms in the current paper in order to isolate and identify a rent-capture mechanism whose sensitivity to assumptions about the nature of product and labour markets we examine. Accordingly, we assume fallback profits to be exogenous and set equal to zero.

After substitution, (21) can be re-written as:

$$
N A_{1 B}^{d}=\left[\frac{1}{4-c_{B}^{2}}\right]^{1+\beta_{B}}\left[w_{1 B}-\bar{w}_{B}\right]^{1-\beta_{B}}\left[\left(2-c_{B}\right) a_{B}-2 w_{1 B}+c_{B} w_{2 B}\right]^{1+\beta_{B}}
$$

From (22), the first-order condition for a maximum is:

$$
\frac{d N A_{1 B}^{d}}{d w_{1 B}}=K\left\{\left(1-\beta_{B}\right)\left[\left(2-c_{B}\right) a_{B}-2 w_{1 B}+c_{B} w_{2 B}\right]-2\left(1+\beta_{B}\right)\left(w_{1 B}-\bar{w}_{B}\right)\right\}=0
$$

where $\mathrm{K}$ is a positive constant.

It follows from (23) that:

(i) $\frac{d w_{1 B}}{d w_{2 B}}=\frac{c_{B}}{4}\left(1-\beta_{B}\right) \geq 0$, that is, the union-firm pair's best-reply function is positively-sloped in wage-space, and

\footnotetext{
12 See, for example, Padilla et alia (1996).

${ }^{13}$ This idea is implicit in much of the recent literature on foreign direct investment and unionisation.
} 
(ii) in a fully symmetric equilibrium within Country B,

$$
w_{B}=w_{1 B}=w_{2 B}=\bar{w}_{B}+\frac{\left(2-c_{B}\right)\left(1-\beta_{B}\right)\left(a_{B}-\bar{w}_{B}\right)}{4-c_{B}\left(1-\beta_{B}\right)}
$$

From (24), it is straightforward to show that $\frac{\partial w_{B}}{\partial \beta_{B}}<0$, and that $\frac{\partial w_{B}}{\partial c_{B}}<0$ for $\beta_{B}<1 .^{14}$

Therefore, consistent with the general analysis conducted in Section 2, an increase in the firms' bargaining power $\beta_{B}$ reduces the equilibrium wage rate, as expected. The degree of product substitutability also affects wages in a predictable way: more competition in the goods market induces wage moderation. This establishes Proposition 4.

Proposition 4 Under FDI, bargained wages are lower the greater the degree of product market substitutability.

\subsection{Stage 1}

Substituting (24) in (15) yields the expression for Firm 1's equilibrium variable (foreign) profits under duopoly in Country B:

$$
\pi_{1 B}{ }^{d}=\left[\frac{2\left(1+\beta_{B}\right)\left(a_{B}-\bar{w}_{B}\right)}{\left(2+c_{B}\right)\left[4-c_{B}\left(1-\beta_{B}\right)\right]}\right]^{2}
$$

From (25), it is easily checked that

$$
\frac{\partial \pi_{1 B}{ }^{\mathrm{d}}}{\partial \beta_{B}}>0
$$

and that

$$
\frac{\partial \pi_{1 B}{ }^{\mathrm{d}}}{\partial c_{B}}<0 \text { for } c_{B}>0
$$

Equation (26) confirms previous results. (27) obtains because, for any given level of union bargaining power, potential capturable rents in the foreign market are decreasing in the degree to which the firms' products are substitutable: and this outweighs the wage-moderation effect described in Proposition 4. Each firm anticipates that a higher degree of product substitutability will be associated with tougher competition in the product market: that is, the

\footnotetext{
${ }^{14}$ Under our assumption that bargaining is decentralised, the equilibrium wage depends on product market competition, see Horn and Wolinsky (1988) for a fuller discussion.
} 
downward-sloping best-reply output functions (implicit in (17) and (18)) become steeper in output-space, as goods become closer substitutes. Therefore, the expectation of tougher competition in the product market discourages FDI.

Recall from the previous Section of the paper that the FDI-indifference schedule of Firm 1 is given by $\pi_{1 B}{ }^{d}-F_{1 B}=0$. Then, from (27), it follows that an increase in $c_{B}$ causes a downward shift in Firm 1's indifference schedule. This is depicted in Figure 3 from which it is clear that the probability of observing RFDI as the sub-game perfect Nash equilibrium is decreasing as product market substitutability increases. This establishes Proposition 5.

Proposition 5 In the presence of unions, the sub-game perfect Nash equilibrium is less likely to be characterised by reciprocal foreign direct investment the greater is the degree of product market substitutability in either or both of the two markets.

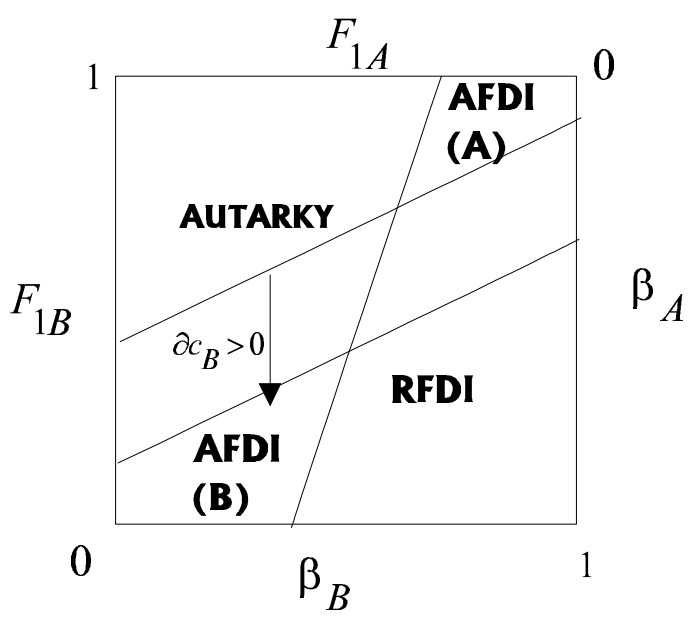

Figure 3

\subsection{The prisoner's dilemma revisited}

In sub-section 2.5, we showed that, under the assumption of symmetry across countries, the FDI game is vulnerable to the problems associated with the prisoner's dilemma. In particular, we showed that RFDI will be a Pareto-dominated Nash equilibrium if condition (10) is satisfied and that this is more likely the greater is the excess of monopoly profits over oligopoly profits. From (27), we know that oligopoly profits are falling in the degree of product market substitutability. On the other hand, we know that monopoly profits, by construction, are not influenced by the extent of substitutability. This establishes Proposition 6. 
As product substitutability increases, the excess of monopoly over oligopoly profits rises and there is a consequent increase in the likelihood that RFDI, in equilibrium, will be Pareto-dominated by Autarky.

In such a situation, the two firms would prefer to collude to prevent entry into each other's domestic market: but, in the nature of the prisoner's dilemma, such collusion is vulnerable to the dominant free-rider incentive to enter the rival's market through FDI. This suggests that firms might develop alternative ways of deterring costly entry by other firms into their markets. One such entry-deterring strategy is the subject of the analysis in Section 4.

\section{$4 \quad$ Unions as a barrier to FDI}

So long as monopoly profits exceed duopoly profits, each firm has an incentive to erect barriers against the entry of the other firm into its own domestic market. Indeed, firms would have an incentive to collude in this if the FDI has prisoners' dilemma characteristics, as discussed in the previous section of the paper. We have also shown that entry by a foreign rival is more likely the weaker is the (common) level of union influence in the potential host country. From this it follows that, potentially, there is an incentive for the domestic firm to encourage strong unions at home as a strategic entry barrier against FDI. ${ }^{15}$

One possible method by which a firm might achieve this is by tolerating a monopoly union in the home industry: i.e., by delegating to the union the role of selecting the wage level. ${ }^{16}$ An alternative for the firm would be to cede to the union not all influence over wages, but just a small amount, say epsilon, in excess of that which would leave the rival firm just indifferent about entry. However, making such fine calculations may be neither feasible nor as 'visible' as complete delegation.

A problem with delegation as an entry-deterring strategy is that the potential entrant may not perceive that they will be bound by the same level of union bargaining as the domestic incumbent. Indeed, it has not been uncommon in the UK for new entrants to attempt to deviate from national or industry-wide bargaining arrangements by establishing either "non-union" agreements, or opt-out clauses from central bargains. For example, new entrants have tended to favour greenfield site developments which lack traditions of union

\footnotetext{
${ }^{15}$ Williamson (1968) is an early example of the use of union influence over wages as an entry-deterring strategy.

${ }^{16}$ The analysis of this section derives from helpful suggestions made by an anonymous referee of this Journal.
} 
representation. ${ }^{17}$ In situations where such opt-outs are possible, the encouragement or 'sponsoring' of strong domestic unions by domestic firms would not be a credible strategy for entry-deterrence.

Suppose, however, that the existence of strong domestic unions did act as a signal to potential foreign entrants of the likely union bargaining power they would have to confront in the host country. ${ }^{18} 19$ Then wage-delegation offers a potential strategy for entry-deterrence by the domestic incumbent. In this case, the willingness of a domestic firm to pre-commit itself to delegating wage determination to a union would depend upon a comparison of the subgame perfect equilibrium profits under (i) entry-induced oligopoly with union influence limited to its 'intrinsic' or non-sponsored extent, and (ii) entry-deterred monopoly with wages delegated to a monopoly union.

Clearly, delegating wage determination offers a potential trade-off to the firm: on the one hand it enables unions to capture a larger share of any given level of rents or surplus, but on the other hand potentially raises the size of the surplus by inhibiting competition. Let us consider the individual firm's problem more formally. We assume fully centralised bargaining at the industry level. ${ }^{20}$

Consider Firm 2. In the event that Firm 1 enters Firm 2's domestic product market in Country B, the oligopoly profits of Firm 2 will be given by:

$$
\pi_{2 B}^{d}=\left[\frac{\left(1+\beta_{B}\right)\left(a_{B}-\bar{w}_{B}\right)}{2\left(2+c_{B}\right)}\right]^{2}=\pi_{1 B}^{d}
$$

(28) derives from (19), (20) and (21) and the fact that $w_{1 B}=w_{2 B}$ under centralised bargaining.

\footnotetext{
${ }^{17}$ The Japanese-owned car-maker Nissan is such an example, see e.g., Garrahan and Stewart (1992).

${ }^{18}$ Effectively, the domestic firm pre-commits itself (and any subsequent entrant) to delegating wages to a monopoly union. This is most likely if wage-bargaining is fully centralised at the industry level, and hence this is the case we consider in this Section. We note that Horn and Wolinsky (1988) have shown centralised bargaining to be preferred by unions for the case of oligopoly in gross substitutes and linear demands.

${ }^{19}$ In a recent empirical paper, Cooke and Noble (1998) find that the incidence of US outward FDI is negatively related to the centralisation of wage negotiations in potential host countries.

${ }^{20}$ The results are also valid if a centralised monopoly union bargains separately with each firm under reasonable assumptions about the union's inside option.
} 
Suppose instead that Firm 2 retains a domestic monopoly. Then it is straightforward to show that its profits are given by:

$$
\pi_{2 B}^{m}=\left[\frac{\left(1+\beta_{B}\right)\left(a_{B}-\bar{w}_{B}\right)}{4}\right]^{2}
$$

The profit expressions (28) and (29) are depicted in Figure 4. Consider Firm 1's FDI choice. Given the level of fixed costs associated with FDI assumed in the figure, ${ }^{21}$ it is clear that if $\beta_{B}<\beta_{B}^{*}$, then Firm 1 will stay out of Country B as unions are so powerful as to render FDI unprofitable: Firm 2 enjoys monopoly profits given by (29). If, on the other hand, $\beta_{B}>\beta_{B}^{*}$ then Firm 1 enters and Firm 2 earns profits given by (28). Clearly, for given $\beta_{B}$, $\pi_{2 B}^{m}>\pi_{2 B}^{d}$.

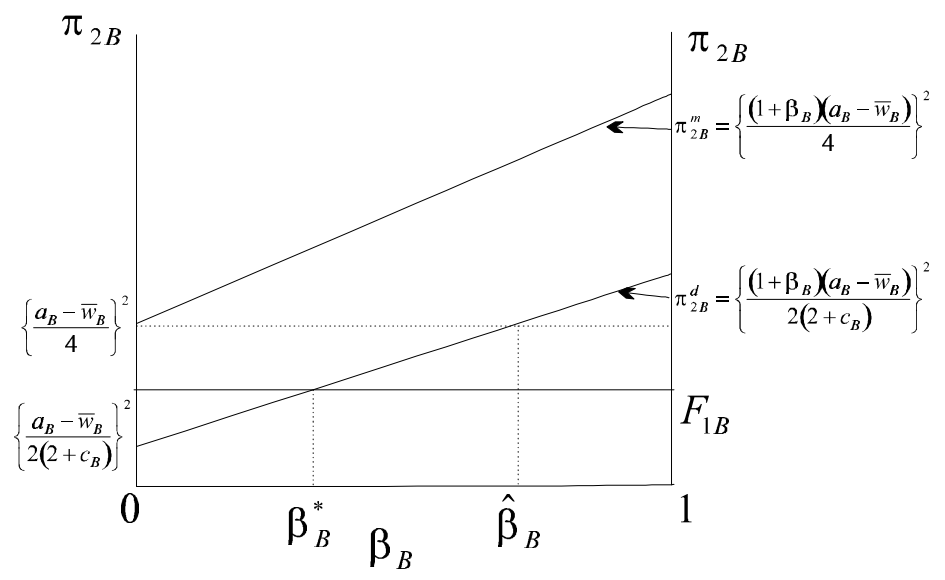

Figure 4

Suppose that Firm 2 pre-commits itself to delegate wage-setting to its union and that this acts as a credible signal to the potential entrant that union wage influence in Country B is absolute $\left(\beta_{B}=0\right)$. Then, with $\beta_{B}^{*}>0$, Firm 2 will have succeeded in deterring entry and will earn profits given by (29) with $\beta_{B}=0$ :

i.e., $\quad \pi_{2 B}^{m}=\left[\frac{\left(a_{B}-\bar{w}_{B}\right)}{4}\right]^{2}$

\footnotetext{
${ }^{21}$ The value of $\mathrm{F}_{1 \mathrm{~B}}$ is chosen for illustrative purposes. It is straightforward to extend our analysis to other assumptions on $\mathrm{F}_{1 \mathrm{~B}}$. In the figure, the indirect profit functions are drawn as linear for simplicity: only monotonicity is important.
} 
Is it profitable for Firm 2 to adopt this strategy? The answer depends upon the underlaying or intrinsic value of $\beta_{B}$. Clearly, if $\beta_{B}<\beta_{B}^{*}$, then such delegation is unnecessary as Firm 1 would anyway prefer not to enter. Similarly, if $\beta_{B}>\beta_{B}^{*}$ delegation is not profitable for Firm 2 as $\pi_{2 B}^{d}\left(. \mid \beta_{B}>\hat{\beta}\right)>\pi_{2 B}^{m}\left(. \mid \beta_{B}=0\right)$ and unions are so weak that duopoly profits under bargaining exceed monopoly profits under wage delegation. Delegation is profitable, therefore, only if $0<\beta_{B}^{*}<\beta_{B}<\hat{\beta}_{B}$. This establishes Proposition 7 .

Proposition 7 A firm's incentive to delegate wage determination to its union depends upon the extent of the union's underlaying influence over wages, and is likely to be greatest for intermediate values of union bargaining power.

Finally, we note that any excess of delegation-supported monopoly profits over unsupported oligopoly profits depends on the values of $F_{1 B}, c_{B}$, and of $\left(a_{B}-\bar{w}_{B}\right)$, the excess of the reservation price over the reservation wage in Country B. This is captured in Proposition 8 .

Proposition 8 The incentive to deter entry through the delegation of wage determination to the union is (i) decreasing in $F_{1 B}$, the fixed cost of FDI, (ii) increasing in $c_{B}$, the degree of (potential) product market substitutability, and (iii) increasing in $\left(a_{B}-\bar{w}_{B}\right)$, the reservation price-wage gap.

Proof. It is clear that the likelihood that Firm 2 has an incentive to pre-commit to wage delegation is positive if the interval $\hat{\beta}_{B}-\beta_{B}^{*}$ is positive, and is increasing in the size of this interval. To demonstrate the proposition, define:

$$
\Delta=\hat{\beta}_{B}\left(c_{B}\right)-\beta_{B}^{*}\left(c, \mathrm{~F}_{\mathrm{B}}, \mathrm{a}_{\mathrm{B}}-\bar{w}_{B}\right)
$$

Then, exploiting (28) and (29), it is straightforward to show that, for $\hat{\beta}_{B}-\beta_{B}^{*}>0$ :

(i) $\frac{d \Delta}{d F_{1 B}}<0$ 
The intuition for this result is simply that a fall in FDI costs increases the likelihood that Firm 1 will choose to invest in Country B, and hence renders strategic entry deterrence by Firm 2 more likely.

(ii) $\frac{d \Delta}{d c_{B}}>0$.

The intuition here is that increased product substitutability increases the incentives for Firm 2 to avoid costly competition, and, given the assumptions of our model, this outweighs the fact that Firm 1 is anyway less likely to conduct FDI the higher is $c_{B}$.

(iii) $\frac{d \Delta}{d\left(a_{B}-\bar{w}_{B}\right)}>0$.

This occurs because an increase in the reservation price-wage gap is likely to stimulate a greater incentive for Firm 1 to invest in Country B, and provokes a greater likelihood of entry deterrence by the domestic incumbent.

\section{Conclusions}

We have considered the FDI decisions confronting firms located in two countries in the context of unionised labour markets and separate imperfectly competitive product markets. We have shown, inter alia, that FDI in a potential host country is more likely the weaker is union wage-bargaining power in that country, and the less is the degree of substitutability between the potential rivals' products. This is because under such conditions, the potential capturable rents associated with FDI will be the greater. We have also derived results on the conditions under which any FDI in sub-game perfect Nash equilibrium will be either one-way (asymmetric) or two-way (reciprocal). These give rise to testable propositions in the light of the evidence cited in the introduction motivating the analysis.

We have shown that it is possible that the FDI game will possess the characteristics of a prisoners' dilemma in which each firm has a dominant incentive to enter the other's domestic market producing a Nash equilibrium which is Pareto-dominated by the outcome in which neither breaks the domestic monopoly of the other. We have shown that this is more likely the greater is the degree of product market substitutability across the two firms' outputs. 
Incumbent domestic monopolists have incentives to deter entry by potential foreign rivals. Indeed, if the FDI game has the above characteristics of the prisoners' dilemma, then it would be in the interests of firms to agree not to enter each other's market. Such collusion is, of course, vulnerable to the dominant strategy to renege on any such agreement. Alternative methods exist to deter entry by potential rival firms. We have examined the possibility that firms might delegate wage-setting to unions in order to deter entry. We have shown that the likelihood of this occurring depends, inter alia, on the extent of union wage influence in the absence of delegation, on the degree of product market substitutability, and on the magnitude of FDI costs.

In our analysis, we have focused on rent-capture incentives to conduct foreign direct investment, examining how firms' behaviour is influenced by both product and labour market characteristics. We have abstracted from the divide-and-rule incentive on which much previous discussion in this field has focused. The key result we obtain is the opposite of the usual result that strong unions drive firms to conduct FDI: the nature of the relationship between FDI strategies and both product and labour market features is therefore likely to be more complex than typically supposed. This is particularly true if firms are able to shape the design of labour market institutions strategically, as we have discussed above.

We identify two directions for further work. First, in the current paper, we consider the situation in which firms choose between FDI and production for the home market only: we do not consider the trade option for firms. To an extent this is justifiable by our focus on service sector industries, the output of which is intrinsically less tradable than goods. However, extending the model to the general case is an obvious next step. Second, we think it would be fruitful to develop an application of the analysis to the case of foreign acquisition through mergers and takeovers. 


\section{References}

Alexander, C.O. and Lendermann, W. (1996). 'Are Nash bargaining wage arrangements unique? An investigation to bargaining sets for firm-union negotiation', Oxford Economic Papers, 48, pp. 242-53.

Barrell, R. and Pain, N. (1997). 'Foreign direct investment, technological change, and economic growth within Europe', Economic Journal, 107, pp. 1770-86.

Bughin, J. and Vannini, S. (1995). 'Strategic direct investment under unionised oligopoly', International Journal of Industrial Organization, 13, pp. 127-45.

Cooke, W.N. and Noble, D.S. (1998). 'Industrial relations systems and US foreign direct investment abroad', British Journal of Industrial Relations, 36, pp.581-609.

Cowling, K. and Sugden, R. (1994). Beyond capitalism: towards a new economic order, Pinter, London.

de Meza, D. (1982). 'Generalised oligopoly derived demand with an application to tax induced entry', Bullettin of Economic Research, 34, pp. 1-16.

Dixit, A. (1986). 'Comparative statics for oligopoly', International Economic Review, 27, pp. 107-22.

Dowrick, S. (1989). ‘Union oligopoly bargaining', Economic Journal, 99, pp. 1123-42.

Dunning, J.H. (1997a). 'The European internal market programme and inbound foreign direct investment: part I', Journal of Common Market Studies, 35, pp.1-30.

Dunning, J.H. (1997b). 'The European internal market programme and inbound foreign direct investment: part II', Journal of Common Market Studies, 35, pp.189-223.

European Commission (1996). 'Trade and foreign direct investment specialisation effects of the single market programme', in 'Economic evaluation of the internal market', European Economy, n.4, pp. 65-113.

Dixit, A. (1986). 'Comparative statics for oligopoly', International Economic Review, 27, pp. 107-22.

Fudenberg, D. and Tirole, J. (1991). Game theory, MIT Press, Cambridge, Massachusetts.

Garrahan, P. and Stewart, P. (1992). The Nissan Enigma: flexibility at work in a local economy, Mansell, London.

Greenaway, D. and Milner, C. (1986). The economics of intra-industry trade, Oxford, Blackwell.

Grout, P. (1984). 'Investment and wages in the absence of binding contracts: a Nash bargaining approach', Econometrica, 58, pp. 449-60. 
Horn, H. and Wolinsky, A. (1988). 'Bilateral monopolies and incentives for merger', Rand Journal of Economics, 19, pp. 408-19.

Horstmann, I.J. and Markusen, J.R. (1987). 'Strategic investment and the development of multinationals', International Economic Review, 28, pp.109-21.

OECD (1991), Employment outlook, Paris.

OECD (1996). OECD reviews of foreign direct investment: France, Paris.

Padilla, A.J., Bentolila, S., and Dolado, J.J. (1996). 'Wage bargaining in industries with market power', Journal of Economics and Management Strategy, 5, pp. 535-64.

Rovida, F. (1995). The effects of unions on investment and innovation decisions, theory and empirical evidence, Phd Thesis, University of Warwick.

Sapir, A. (1993). 'Sectoral dimension', in 'Market services and European integration', European Economy, n. 3, pp. 25-39.

Seade, J. (1985). 'Profitable cost increases and the shifting of taxation', Warwick Economic Research Paper, n. 260.

Singh, N. and Vives, X. (1984). 'Price and quantity competition in a differentiated duopoly', Rand Journal of Economics, 15, pp. 547-53.

Smith, A. (1987). 'Strategic investment, multinational corporation and trade policy', European Economic Review, 31, pp. 89-96.

Williamson, O.E. (1968). 'Wage rates as a barrier to entry: the Pennington case in perspective', Quarterly Journal of Economics, 82, pp. 85-116.

Zhao, L. (1995). 'Cross-hauling direct foreign investment and unionised oligopoly', European Economic Review, 39, pp. 1237-53.

Zhao, L. (1998). 'The impact of foreign direct investment on wages and employment', Oxford Economic Papers, 50, pp. 284-301. 


\section{Appendix 1: Proof of Lemma 2.}

Consider country B. The profit function of firm $\mathrm{i}=\{1,2\}$ is:

$\pi^{d}{ }_{i B}=\left[p_{B}\left(x_{1 B}+x_{2 B}\right)-w_{i B}\right] x_{i B}$

where $\mathrm{p}_{\mathrm{B}}$ is twice continuously differentiable, with $p^{\prime}{ }_{B}<0 ; x_{i_{\mathrm{B}}}$ and $\mathrm{w}_{\mathrm{i}_{B}}$ are the output and wage rate in firm $i=\{1,2\}$, respectively. Wages are predetermined at this stage. The firstorder conditions in the Cournot game are:

$\frac{\partial \pi^{d}{ }_{i B}}{\partial x_{i B}}=p_{B}+p^{\prime}{ }_{B} x_{i B}-w_{i B} \leq 0$, and $\mathrm{x}_{\mathrm{iB}} \geq 0$ with complementary slackness

for $\mathrm{i}=\{1,2\}$. We assume the following:

$\frac{\partial^{2} \pi^{d}{ }_{i B}}{\left(\partial x_{i B}\right)^{2}}=2 p^{\prime}{ }_{B}+p^{\prime \prime}{ }_{B} x_{i B}<0 ; \frac{\partial \pi^{d}{ }_{i B}}{\partial x_{1 B} \partial x_{2 B}}=p^{\prime}{ }_{B}+p^{\prime \prime}{ }_{B} x_{i B}<0, \mathrm{i}=\{1,2\}$

Therefore, firms play in strategic substitutes, which is the standard case in quantity competition. (A.3) and continuity of the profit functions in outputs are sufficient for the existence of a pure-strategy Nash equilibrium (cf. e.g., Fudenberg and Tirole, 1991, Theorem 1.2). The following conditions imply uniqueness and stability of the equilibrium as well (cf. e.g., Dixit, 1986):

$$
\begin{aligned}
& D \equiv\left[\frac{\partial^{2} \pi^{d}{ }_{1 B}}{\left(\partial x_{1 B}\right)^{2}}\right]\left[\frac{\partial^{2} \pi^{d}{ }_{2 B}}{\left(\partial x_{2 B}\right)^{2}}\right]-\left[\frac{\partial \pi^{d}{ }_{1 B}}{\partial x_{1 B} \partial x_{2 B}}\right]\left[\frac{\partial \pi^{d}{ }_{2 B}}{\partial x_{2 B} \partial x_{1 B}}\right]=\left(p_{B}^{\prime}\right)^{2}(3-E)>0 \\
& T R \equiv \frac{\partial^{2} \pi^{d}{ }_{1 B}}{\left(\partial x_{1 B}\right)^{2}}+\frac{\partial^{2} \pi^{d}{ }_{2 B}}{\left(\partial x_{2 B}\right)^{2}}=p^{\prime}{ }_{B}(4-E)<0
\end{aligned}
$$

where $E \equiv-\left(x_{1 B}+x_{2 B}\right) \frac{p^{\prime \prime}}{p_{B}^{\prime}{ }_{B}}=1+\frac{1}{\varepsilon}+\frac{d \log \varepsilon}{\operatorname{dog}\left(\mathrm{x}_{1 \mathrm{~B}}+x_{2 B}\right)}$ is Seade's (1985, p. 32, footnote 7) elasticity of the slope of market demand; $\varepsilon$ and $\frac{d \log \varepsilon}{\operatorname{dlog}\left(\mathrm{x}_{1 \mathrm{~B}}+x_{2 B}\right)}$ denote the (absolute value of the) elasticity of market demand, and the output elasticity of the elasticity of demand, respectively. Starting from a symmetric equilibrium, totally differentiating (A.2) with respect to $x_{1 B}=x_{2 B}=x^{*}$, and $\mathrm{w}_{1 \mathrm{~B}}=w_{2 B}=w^{*}$, assuming $d w_{2 B} / d w_{1 B}=d w_{1 B} / d w_{2 B}=0$, and using 
Cramer's rule, it follows that: $\frac{d x_{1 B}}{d w^{*}}=\frac{d x_{2 B}}{d w^{*}}=\frac{p^{\prime}}{D}<0$. Indirect profits in firm $\mathrm{i}=\{1,2\}$ are written: $\pi^{d}{ }_{i B}=\left[p_{B}\left(2 x^{*}\right)-w^{*}\right] x^{*}$. Totally differentiating with respect to $\mathrm{x}^{*}$ and $\mathrm{w}^{*}$, and using (A.2) to eliminate $\left(p_{B}-w^{*}\right)$, yields: $\frac{d \pi^{d}{ }_{i B}}{d w^{*}}=\frac{\left(p^{\prime}{ }_{B}\right)^{2} x^{*}}{D}[E-2]<0$, using (A.3) and the definition of E. This establishes Lemma 2.

\section{Appendix 2: Proof of Lemma 3.}

In country B, there is a wage bargaining between each firm and union at the plant level. The Nash product in firm $\mathrm{i}=\{1,2\}$ is

$$
N A_{i B}=\left[\pi^{d}{ }_{i B}\left(w_{1 B}, \mathrm{w}_{2 \mathrm{~B}}\right)\right]^{\beta_{\mathrm{B}}}\left[S\left(w_{1 B}, \mathrm{w}_{2 \mathrm{~B}}\right)\right]^{1-\beta_{B}}
$$

where $S_{i B}=\left[u\left(w_{i B}\right)-u\left(\bar{w}_{B}\right)\right]\left[x_{i B}\left(w_{1 B}, \mathrm{w}_{2 \mathrm{~B}}\right)\right]^{\theta}$ is the union's utility, and $\theta \geq 0$ is the union's relative preference for employment. (A.5) assumes that conflict payoffs are zero, $\bar{\pi}_{B}=\bar{S}_{B}=0 ; 0<\beta_{\mathrm{B}}<1$ denotes the exogenous firm's bargaining power, which we assume symmetric between plants. In each plant, the wage bargaining occurs simultaneously and independently, taking as given the outcome of the wage negotiation in the other plant. Taking logs of (A.5), the first-order conditions are:

$\frac{\partial \log N A_{i B}}{\partial w_{i B}}=\beta_{\mathrm{B}} \frac{\partial \log \pi_{i B}^{\mathrm{d}}}{\partial w_{i B}}+\left(1-\beta_{\mathrm{B}}\right) \frac{\partial \log S_{i B}}{\partial w_{i B}} \leq 0$, and $\mathrm{w}_{\mathrm{iB}} \geq 0$ with complementary slackness

(A.6) for $\mathrm{i}=\{1,2\}$.

We assume that the following conditions hold:

$\frac{\partial^{2} \log N A_{i B}}{\left(\partial w_{i B}\right)^{2}}<0 ; \frac{\partial^{2} \log N A_{i B}}{\left(\partial w_{1 B}\right)\left(\partial w_{2 B}\right)}>0$

for $\mathrm{i}=\{1,2\}$. Therefore, we assume that the wage game is played in strategic complements. Provided a solution to the Nash bargaining problem in each plant exists and is unique (see Alexander and Lendermann, 1996, for a discussion), there also exists a pure-strategy Nash equilibrium in the $w_{i B}\left[\bar{w}_{B}, \mathrm{p}_{\mathrm{B}}\right)$ space, if the payoff functions $N A_{i B}$ are continuous in wages 
and quasi concave in its own wage. Moreover, the equilibrium is unique and stable, when the following conditions hold:

$$
\begin{aligned}
& D 2 \equiv\left[\frac{\partial^{2} \log N A_{1 B}}{\left(\partial w_{1 B}\right)^{2}}\right]\left[\frac{\partial^{2} \log N A_{2 B}}{\left(\partial w_{2 B}\right)^{2}}\right]-\left[\frac{\partial^{2} \log N A_{1 B}}{\left(\partial w_{1 B}\right)\left(\partial w_{2 B}\right)}\right]\left[\frac{\partial^{2} \log N A_{2 B}}{\left(\partial w_{2 B}\right)\left(\partial w_{1 B}\right)}\right]>0 \\
& T R 2 \equiv \frac{\partial^{2} \log N A_{1 B}}{\left(\partial w_{1 B}\right)^{2}}+\frac{\partial^{2} \log N A_{2 B}}{\left(\partial w_{2 i B}\right)^{2}}<0
\end{aligned}
$$

Solving (A.6), gives the wage rates as a function of the bargaining power and union's preference parameters at a symmetric equilibrium: $w_{1 B} *=w_{2 B} *=w^{*}\left(\beta_{B}, \theta\right)$. Totally differentiating (A.6) with respect to $w_{1 B}^{*}=w_{2 B} *=w^{*}$ and $k_{B}=\left\{\beta_{B}, \theta\right\}$, and applying Cramer's rule, it follows that a common increase either in the firm's bargaining power or in the union's preference for employment has the following effects on $w_{1 B} *$ (the effect on $w_{2 B} *$ is the same):

$\frac{d w_{1 B} *}{d k_{B}}=\left\{\frac{-\left[\frac{\partial^{2} \log N A_{1 B}}{\left(\partial w_{1 B}\right)\left(\partial k_{B}\right)}\right]\left[\frac{\partial^{2} \log N A_{2 B}}{\left(\partial w_{2 B}\right)^{2}}\right]+\left[\frac{\partial^{2} \log N A_{2 B}}{\left(\partial w_{2 B}\right)\left(\partial k_{B}\right)}\right]\left[\frac{\partial^{2} \log N A_{1 B}}{\left(\partial w_{1 B}\right)\left(\partial w_{2 B}\right)}\right]}{D 2}\right\}<0$

$\frac{\partial^{2} \log N A_{1 B}}{\left(\partial w_{1 B}\right)\left(\partial \beta_{B}\right)}=\frac{\partial \log \pi^{d}{ }_{1 B}}{\partial w_{1 B}}-\frac{\partial \log S_{1 B}}{\partial w_{1 B}}=\left(\frac{1}{1-\beta_{B}}\right) \frac{\partial \log \pi^{d}{ }_{1 B}}{\partial w_{1 B}}<0$

$\frac{\partial^{2} \log N A_{2 B}}{\left(\partial w_{2 B}\right)\left(\partial \beta_{B}\right)}=\frac{\partial \log \pi_{2 B}^{d}}{\partial w_{2 B}}-\frac{\partial \log S_{2 B}}{\partial w_{2 B}}=\left(\frac{1}{1-\beta_{B}}\right) \frac{\partial \log \pi_{2 B}^{d}}{\partial w_{2 B}}<0$

$\frac{\partial^{2} \log N A_{1 B}}{\left(\partial w_{1 B}\right)(\partial \theta)}=\left(1-\beta_{B}\right) \frac{\partial \log x_{1 B}}{\partial w_{1 B}}<0$

$\frac{\partial^{2} \log N A_{2 B}}{\left(\partial w_{2 B}\right)(\partial \theta)}=\left(1-\beta_{B}\right) \frac{\partial \log x_{2 B}}{\partial w_{2 B}}<0$

where we have made use of (A.6) in order to eliminate $\frac{\partial \log S_{i B}}{\partial w_{i B}}, \mathrm{i}=\{1,2\}$, and of (A.7), (A.8). and Lemma 2. (A.9) establishes Lemma 3. 